\title{
Types and stages of vascular remodeling in Dupuytren's contracture (analysis of 506 arteries in the surgical material of 111 patients)
}

\author{
N.A. Shchudlo, T.N. Varsegova, T.A. Stupina, M.M. Shchudlo
}

Ilizarov National Medical Research Centre for Traumatology and Orthopedics, Kurgan, Russian Federation

\begin{abstract}
Purpose Analysis of the severity and staging of pathomorphological changes in the arteries of palmar aponeurosis in patients with Dupuytren's contracture of different age groups Materials and methods Analysis of case records of patients younger than 50 years old $(n=19$, group 1$)$, from 50 to 65 years old $(n=60$, group 2$)$ and over 65 years old $(n=32$, group 3). Light microscopy of paraffin sections of palmar aponeurosis fragments resected in partial fasciectomy and histomorphometry of palmar aponeurosis arteries of three calibers: small (outer diameter less than 150 microns), medium (150-300 microns), large (more than 300 microns). Control samples - fragments of the aponeurosis of three patients younger than 50 years old with hand injuries. Results Groups 1-3 are comparable in terms of fibromatosis duration, frequency of lesions in both hands, and the number of fingers with impaired function, but in group 3 the frequency of contractures in advanced stages and cardiovascular diseases was higher $(p<0.05)$. In arteries of small caliber, obliterating lesions and signs of expansive remodeling were also encountered; in arteries of medium caliber, expansive remodeling prevailed; in arteries of large caliber, constrictive remodeling was expressed. Discussion The types of remodeling identified were found in all age groups. Based on the results of the study and the data obtained earlier, 6 stages of pathomorphological changes in the vessels of the palmar aponeurosis were identified in Dupuytren's contracture. Conclusion Dupuytren's contracture refers to diseases mediated by vascular remodeling, affecting mainly the arterial bed, the severity and staging of which does not depend on the age of a patient.
\end{abstract}

Keywords: Dupuytren's contracture, palmar aponeurosis, arteries, histomorphometry

\section{INTRODUCTION}

Dupuytren's contracture refers to superficial fascial fibromatosis. Nodular and fibrous thickening of the bands of the palmar aponeurosis extends to the fingers, may cause limitation of their extension, and persistent flexion deformities of the hand which impair daily activity and professional skills [1]. Various minimally invasive and open surgeries aimed at destruction or removal of pathological foci and correction of deformations improve the function and esthetic appearance of the hand but do not prevent relapse of the disease [2]. Re-operations are technically difficult even for experienced surgeons, and the risk of complications increases [3]. The effectiveness of all currently known methods of conservative treatment of the disease remains unproven [4], but there is a great need for etiopathogenetic therapy of fibromatosis, which would prevent its progression at the initial stage or prevent relapse in patients who were operated.

The role of myofibroblasts, growth factors and cytokines, matrix metalloproteinases, free radicals, sex hormones, changes in gene expression and mechanical stimulation in the development of fibromatosis has been intensively studied over the past decades [5], but the etiology of the disease remains undetermined.

It is assumed that a combination of hereditary and external factors, the aging process, and metabolic disorders associated with concomitant diseases affects the endothelium of blood microvasculature and causes chronic tissue hypoxia, accumulation of immune cells as well as overproduction of cytokines, the mediators of inflammation and fibromatosis [6], that stimulate the proliferation and contractile activity of myofibroblasts as well as collagen overproduction in the nodes and chords of the palmar aponeurosis.

Cell proliferates and collagen deposition cause strangulation of larger vessels and exacerbate hypoxia [7]. Many patients have constriction of the digital arteries and the palmar arch [8], along with structural remodeling of the arteries of the palmar aponeurosis, but its patterns and dependence on age are unknown.

The aim of the study was to analyze the severity and staging of pathomorphological changes in the arteries of the palmar aponeurosis in patients of different age groups diagnosed with Dupuytren's contracture.

\section{MATERIAL AND METHODS}

Case records and surgical material of 111 patients with Dupuytren's contracture operated on at the
Russian Ilizarov Scientific Centre for Restorative Traumatology and Orthopaedics in the period 2014- 
2018 were studied. The age of patients ranged from 27 to 82 years. The exclusion criterion was a history of multiple trauma and injuries of the hand. The study was conducted in accordance with the ethical standards set forth in the Helsinki Declaration of the World Medical Association "Ethical Principles for the Conduct of Scientific Medical Research with the Human Participation" as amended in 2013, approved by the ethics committee of the institution (protocol No. 2 (57) of 03/19/2018). Patients signed an informed consent to publish the results without their identification.

Three groups were distinguished for comparison. Group 1 patients were younger than 50 years old $(n=19)$, those aged from 50 to 65 years old were group $2(n=60)$ and older than 65 years old were group $3(n=32)$. Comparison criteria: duration of palmar fascial fibromatosis (from the moment the areas of palm skin tightening appeared), both hands involvement, number of fingers with impaired function, stage of Dupuytren's contracture according to the Tubiana classification [9].

Fragments of the palmar aponeurosis that were excised during the partial fasciectomy were poured into paraffin blocks according to the standard procedure after being fixed in $4 \%$ formalin and Buen fluid. Slices (5-7 $\mu \mathrm{m})$ produced on a Reichert microtome (Austria), stained with hematoxylin and eosin, van Gieson picrofuxin and Masson's three-color method, were examined under an AxioScope.A1 microscope, and the images were digitized with an AxioCam camera (Carl Zeiss MicroImaging $\mathrm{GmbH}$, Germany). Histomorphometric studies were performed using the VideoTesT Master Morphology 4.0 software. In cross sections of 506 blood vessels of the palmar aponeurosis, the outer diameter, lumen diameter, intima thickness, media thickness were measured; the Kernogan index was calculated as the ratio of media thickness to lumen diameter. Control micropreparations of palmar aponeurosis (group 0 ) were harvested from three patients younger than 50 years old with acute open hand injury.

The data in the tables are presented as medians and quartiles (Me (Q1; Q3)). Hypotheses on difference were tested using nonparametric Wilcoxon criteria and Fisher's exact test in the Attestat computer program version 9.3.1 (developed by I.P. Gaydyshev, certificate of Rusian patent No. 2002611109).

\section{RESULTS}

The patient samples did not have statistically significant differences in the duration of palmar fascial fibromatosis (from the moment of the appearance of tightening areas under the skin of the palm), the frequency of damage to both hands and the number of

fingers with impaired function, but the older age group differed from the other two in severity (Table 1).

Group 3 significantly differed from group 2 in a higher rate of cardiovascular diseases; in group 1 , cardiovascular diseases were not detected (Table 2).

Table 1

Main clinical features in the patients

\begin{tabular}{|c|c|c|c|c|}
\hline Parameter/group & $\begin{array}{c}\text { Duration of } \\
\text { fibromatosis (years) }\end{array}$ & $\begin{array}{c}\text { Rate of lesions in both } \\
\text { hand }\end{array}$ & $\begin{array}{c}\text { Number of affected } \\
\text { fingers }\end{array}$ & Contracture severity \\
\hline Group 1 & $5(3 \div 8)$ & $33.33 \%$ & $1(1 \div 2)$ & $2.5(2 \div 3)$ \\
\hline Group 2 & $5(4 \div 10)$ & $46.55 \%$ & $2(1 \div 3)$ & $2.5(2 \div 3)$ \\
\hline Group 3 & $7(4 \div 11)$ & $51.72 \%$ & $2(1 \div 2)$ & $3(2.25 \div 3)^{*}$ \\
\hline
\end{tabular}

Note: * - significant differences from groups 1 and 2 according to the Wilcoxon criterion $(\mathrm{p}<0.05)$

Table 2

Comorbidities and health problems in the groups

\begin{tabular}{|c|c|c|c|}
\hline Comorbidities & Group 1 & Group 2 & Group 3 \\
\hline Ledderhose disease & $1(5.26 \%)$ & $3(5.00 \%)$ & 0 \\
\hline Cardiovascular diseases & 0 & $24(40 \%)^{*}$ & $23(71.88 \%)^{*}$ \\
\hline Liver disease & $1(5.26 \%)$ & $11(18.3 \%)$ & $5(15.63 \%)$ \\
\hline Chronic obstructive pulmonary disease & 0 & $5(8.33 \%)$ & $6(18.75 \%)$ \\
\hline Obesity & $1(5.26 \%)$ & $3(5.00 \%)$ & $1(3.13 \%)$ \\
\hline Hyperglycemia, diabetes & 0 & $7(11.67 \%)$ & $5(15.63 \%)$ \\
\hline Urolithiasis disease & 0 & $2(3.33 \%)$ & 0 \\
\hline History of tuberculosis & 0 & $2(3.33 \%)$ & 0 \\
\hline History of cancer & 0 & $1(1.67 \%)$ & 0 \\
\hline Sensorineural hearing loss & 0 & $3(5.00 \%)$ & $5(15.63 \%)$ \\
\hline Epilepsy & 0 & 0 & $2(6.25 \%)$ \\
\hline Extreme smoking & $3(15.79 \%)$ & $8(1.33 \%)$ & $2(6.25 \%)$ \\
\hline
\end{tabular}

Note: $*$ - intergroup differences by Fisher's exact criterion $(\mathrm{p}<0.05)$ 
A histological examination revealed that in the control group (without signs of fascial fibromatosis), the outer diameters of the arteries of the normal palmar aponeurosis form three ranges (50-127, 161-224 and 334-610 $\mu \mathrm{m}$ ). Thus, it was possible to distinguish arteries of small, medium and large calibers. In patients with Dupuytren's contracture, size ranges were similar but wider (50-149, 157-299, 300-662 $\mu \mathrm{m})$. Most arteries were characterized by adventitious fibrosis in a pathologically altered aponeurosis (Fig. 1, a, c, d; Fig. 2, f; Fig. 3, a, b) and an increased number of vasa vasorum (Fig. 1, $d$ and Fig. 3, f). In some arteries, adventitia contained accumulations of smooth muscle cells (Fig. 1, c and Fig. 3, f). Among the arteries of large and medium caliber, there were vessels with narrowed and deformed lumens, a densely folded inner elastic membrane and contracted smooth muscle cells in the media (Fig. 1, a, b and Fig. 2, a). In the inner layer of the media, foci of hyperplasia and lymphocytic macrophage infiltration were noted (Fig. $1 \mathrm{c}, \mathrm{d}$ and Fig. 3, f). Specific staining detected partial (Fig. 2, d) or complete destruction (Fig. 1, e) of the inner elastic membrane, often associated with a pronounced neointimal thickening with polymorphic cells (Fig. 1, e, f and Fig. 2, b). There was partial (Fig. 3, e) or complete obliteration of the lumen, fibrosis of neointimal thickening in the arteries of medium and small caliber (Fig. 3, e). Recanalized thrombi (Fig. 2, e) and plexiform structures (Fig. 2, f) were revealed in the arteries of medium caliber distal to the occlusion level. Small-caliber arteries with an enlarged preserved lumen and an internal elastic membrane frequently had an altered luminal lining: along with hypertrophied endotheliocytes, desaturation of the endothelium and its replacement by neointimal cells were observed (Fig. 3, a, d).
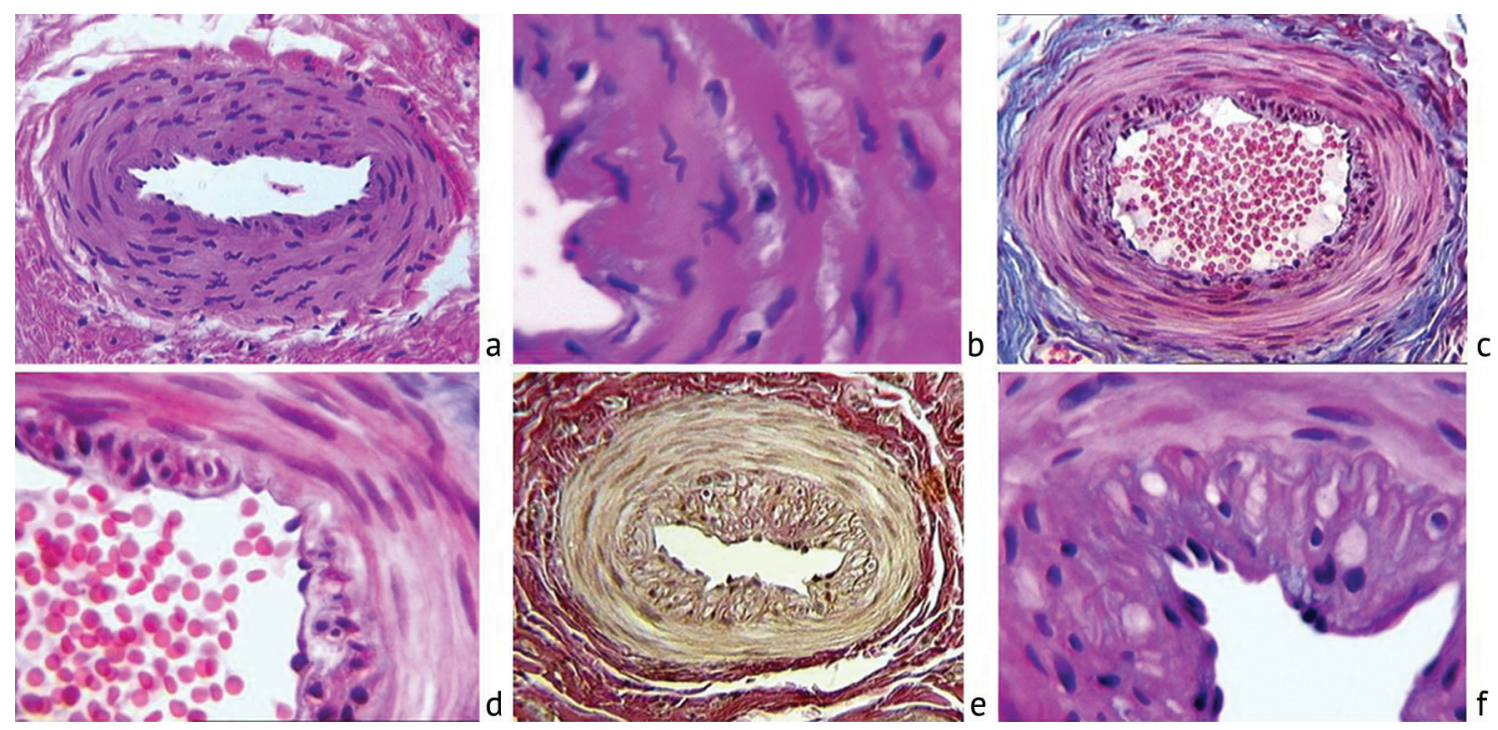

Fig. 1 Transverse paraffin sections of the arteries of the palmar aponeurosis of large caliber (more than 300 microns) from the surgical material of patients with Dupuytren's contracture. Stained with hematoxylin and eosin $(\boldsymbol{a}, \boldsymbol{b}, \boldsymbol{e})$, picrofuchsin according to van Gieson $(\boldsymbol{e})$ and the three-color method according to Masson $(\boldsymbol{c}, \boldsymbol{d})$. Lens 16, eye piece $10(\boldsymbol{a}, \boldsymbol{c}, \boldsymbol{d})$; lens 40, eyepiece $10(\boldsymbol{b}, \boldsymbol{d}, \boldsymbol{f})$
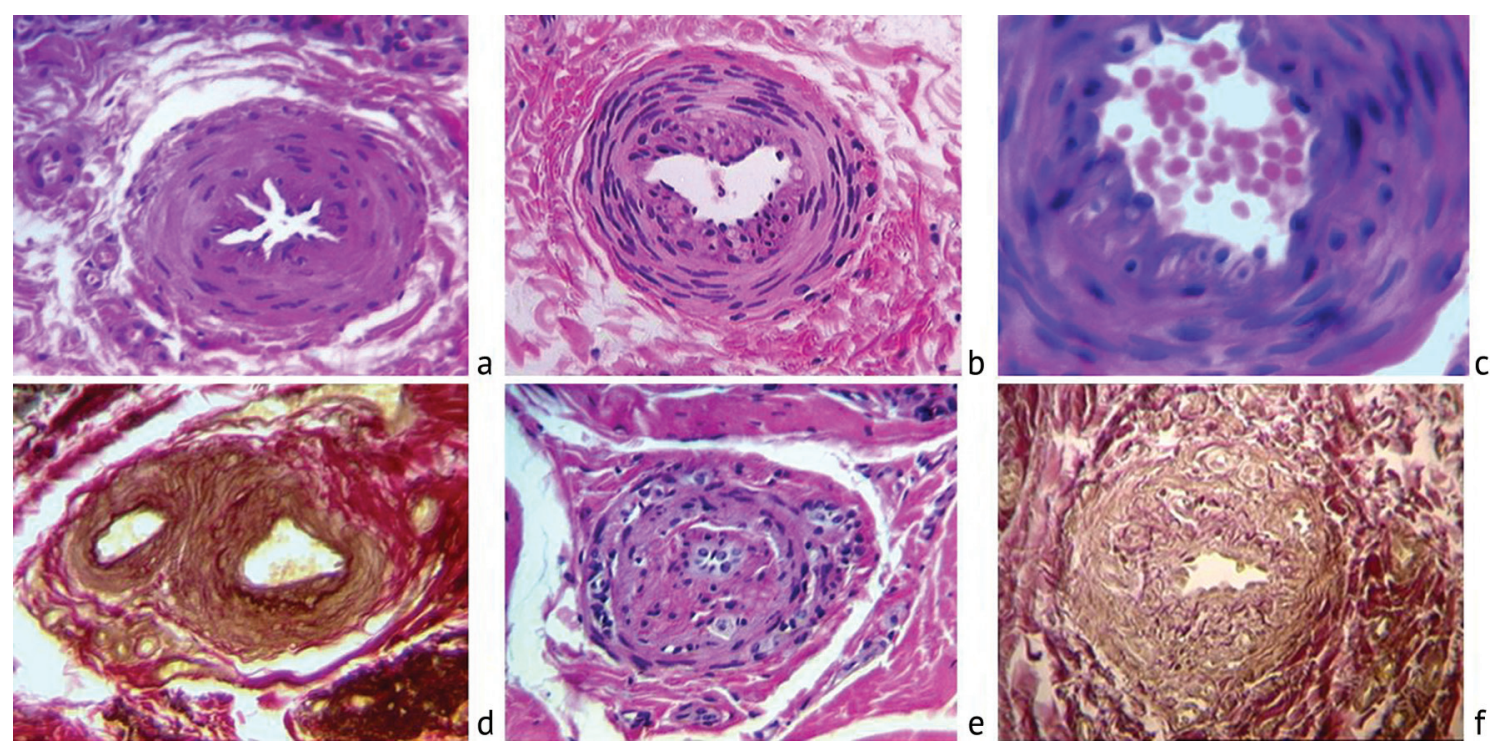

Fig. 2 Transverse paraffin sections of the arteries of the palmar aponeurosis of medium caliber (150-300 microns) from the surgical material of patients with Dupuytren's contracture. Stained with hematoxylin and eosin $(\boldsymbol{a}-\boldsymbol{c}, \boldsymbol{e})$, picrofuchsin according to van Gieson $(\boldsymbol{d}, \boldsymbol{f})$. Lens 16 , eyepiece $10(\boldsymbol{a}, \boldsymbol{c}, \boldsymbol{d})$; lens 40 , eyepiece $10(\boldsymbol{b}, \boldsymbol{d}, \boldsymbol{f})$ 

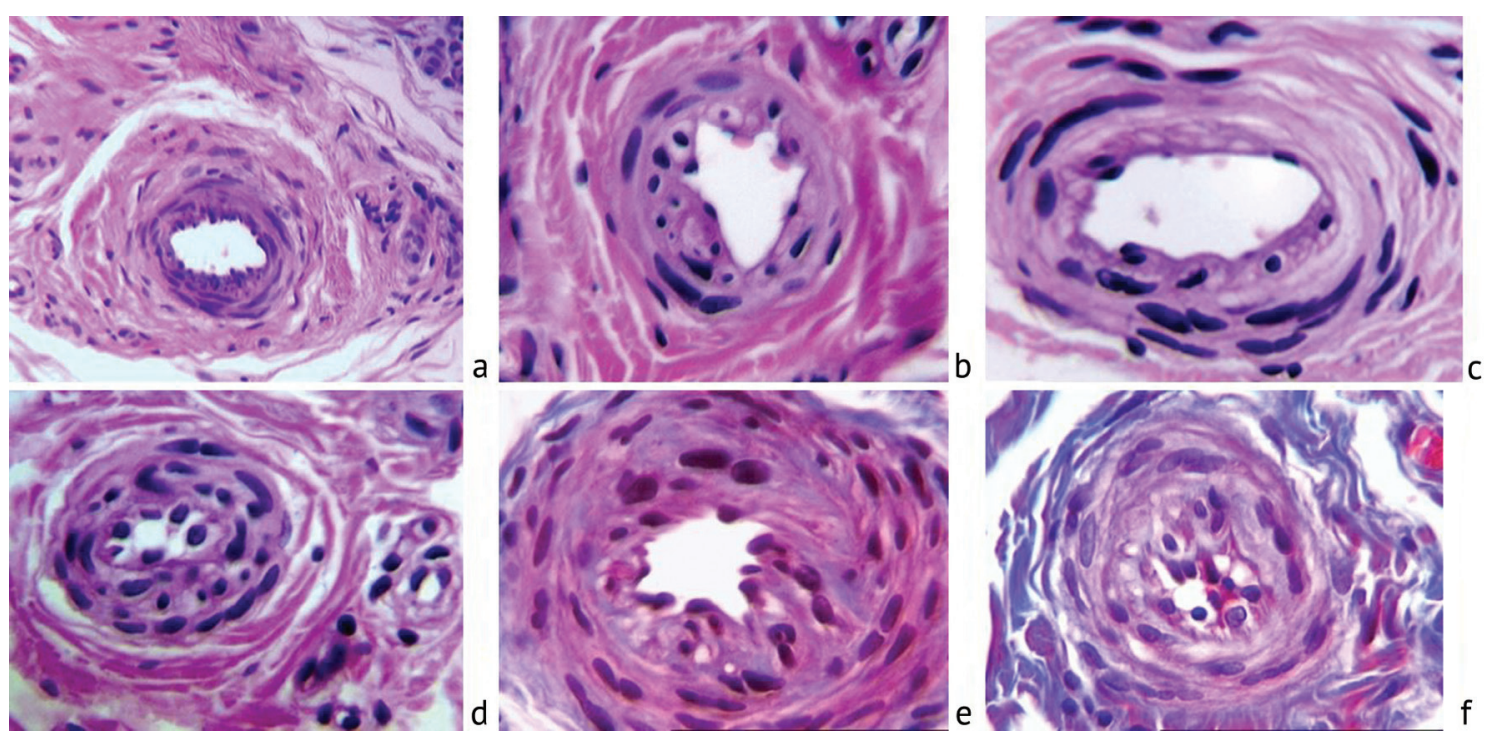

Fig. 3 Transverse paraffin sections of the the palmar aponeurosis arteries of small caliber (50-150 microns) from the surgical material of patients with Dupuytren's contracture. Stained with hematoxylin and eosin $(\boldsymbol{a}-\boldsymbol{d})$, three-color method according to Masson $(\boldsymbol{e}, \boldsymbol{f})$. Lens 16, eyepiece $10(\boldsymbol{a})$; lens 40, eyepiece $10(\boldsymbol{b}-\boldsymbol{e})$

Histomorphometric analysis showed that the diameters of the lumens of the small arteries of the palmar aponeurosis in the patients with Dupuytren's contracture had an increased interquartile range, compared to the control group; in older age groups (2 and 3 ) the lumen diameter was significantly increased compared to the control group, and the thickness of the intima was also increased (Table 3)

Not only the thickness of the intima but also of the media was significantly increased in the arteries of the medium caliber when compared with the control group; and in the older age group (3), the lumen and the outer diameter were both increased when compared with the control and younger patients (group 2).

In large-caliber arteries in all age groups, the outer diameter and the lumen diameter were reduced, and the thickness of the intima was increased against the control group. The intergroup differences were statistically insignificant.

Table 3

Histomorphometric characteristics of arteries (median, $25 \div 75$ percentile)

\begin{tabular}{|c|c|c|c|c|c|c|}
\hline Caliber & Group & External diameter & $\begin{array}{c}\text { Diameter of } \\
\text { lumen }\end{array}$ & $\begin{array}{c}\text { Thickness of } \\
\text { intima }\end{array}$ & $\begin{array}{c}\text { Thickness of } \\
\text { media }\end{array}$ & Kernogan Index \\
\hline \multirow{4}{*}{$\begin{array}{c}50-150 \\
\mu \mathrm{m}\end{array}$} & Group 0 & $\begin{array}{c}86.86 \\
(67.62-98.19)\end{array}$ & $\begin{array}{c}39.72^{3} \\
(31.67-45.27)\end{array}$ & $\begin{array}{c}2.44^{123} \\
(1.87-2.90)\end{array}$ & $\begin{array}{c}16.34 \\
(10.68-19.48)\end{array}$ & $\begin{array}{c}0.54^{13} \\
(0.40-0.63)\end{array}$ \\
\hline & $\begin{array}{c}\text { Age up to } 50 \text { years } \\
\text { Group } 1\end{array}$ & $\begin{array}{c}80.28 \\
(65.50-102.30)\end{array}$ & $\begin{array}{c}33.58^{23} \\
(17.41-61.09)\end{array}$ & $\begin{array}{c}4.20^{03} \\
(2.69-7.75)\end{array}$ & $\begin{array}{c}16.10^{3} \\
(13.69-21.60)\end{array}$ & $\begin{array}{c}0.95^{023} \\
(0.46-1.45)\end{array}$ \\
\hline & $\begin{array}{c}\text { Age } 51-65 \text { Group } \\
2\end{array}$ & $\begin{array}{c}84.75 \\
(70.35-102.45)\end{array}$ & $\begin{array}{c}42.55^{13} \\
(24.72-75.61)\end{array}$ & $\begin{array}{c}5.31^{0} \\
(3.13-7.81)\end{array}$ & $\begin{array}{c}15.60^{3} \\
(11.80-20.25)\end{array}$ & $\begin{array}{c}0.68^{23} \\
(0.39-1.10)\end{array}$ \\
\hline & $\begin{array}{c}\text { Age above } 65 \\
\text { Group } 3\end{array}$ & $\begin{array}{c}84.75 \\
(65.20-98.08) \\
\end{array}$ & $\begin{array}{c}42.55^{012} \\
(44.08-72.55)\end{array}$ & $\begin{array}{c}5.31^{01} \\
(3.68-9.08)\end{array}$ & $\begin{array}{c}15.60^{12} \\
(11.16-16.00)\end{array}$ & $\begin{array}{c}0.43^{012} \\
(0.37-0.54)\end{array}$ \\
\hline \multirow{4}{*}{$\begin{array}{c}150-300 \\
\mu \mathrm{m}\end{array}$} & Group 0 & $\begin{array}{c}183.30^{3} \\
(177.54-205.57)\end{array}$ & $\begin{array}{c}96.61^{3} \\
(94.44-99.39) \\
\end{array}$ & $\begin{array}{c}2.85^{123} \\
(2.55-3.71)\end{array}$ & $\begin{array}{c}24.45^{123} \\
(24.17-24.73)\end{array}$ & $\begin{array}{c}0.43^{12} \\
(0.41-0.44)\end{array}$ \\
\hline & $\begin{array}{c}\text { Age up to } 50 \text { years } \\
\text { Group } 1 \\
\end{array}$ & $\begin{array}{c}199.04 \\
(175.14-200.83) \\
\end{array}$ & $\begin{array}{c}115.64 \\
(85.55-139.86) \\
\end{array}$ & $\begin{array}{c}11.96^{0} \\
(9.89-15.91) \\
\end{array}$ & $\begin{array}{c}33.36^{0} \\
(25.28-37.53) \\
\end{array}$ & $\begin{array}{c}0.55^{0} \\
(0.44-0.84) \\
\end{array}$ \\
\hline & \begin{tabular}{|c|} 
Age 51-65 Group \\
2 \\
\end{tabular} & $\begin{array}{c}199.38^{3} \\
(176.16-203.81) \\
\end{array}$ & $\begin{array}{c}100.15^{3} \\
(65.10-145.23)\end{array}$ & $\begin{array}{c}14.32^{0} \\
(10.58-19.03)\end{array}$ & $\begin{array}{c}32.24^{03} \\
(29.56-41.43)\end{array}$ & $\begin{array}{c}0.61^{0} \\
(0.39-1.13)\end{array}$ \\
\hline & $\begin{array}{c}\text { Age above } 65 \\
\text { Group } 3\end{array}$ & $\begin{array}{c}223.78^{02} \\
(191.89-254.38)\end{array}$ & $\begin{array}{c}122.49^{02} \\
(77.52-199.22)\end{array}$ & $\begin{array}{c}15.00^{0} \\
(11.74-21.81)\end{array}$ & $\begin{array}{c}34.22^{02} \\
(30.37-44.17) \\
\end{array}$ & $\begin{array}{c}0.57 \\
(0.31-0.80)\end{array}$ \\
\hline \multirow{4}{*}{$\begin{array}{c}\text { More } \\
\text { than } \\
300 \mu \mathrm{m}\end{array}$} & Group 0 & $\begin{array}{c}412.80^{123} \\
(351.43-506.31)\end{array}$ & $\begin{array}{c}243.15^{123} \\
(223.07-326.52) \\
\end{array}$ & $\begin{array}{c}8.41^{123} \\
(7.80-10.82) \\
\end{array}$ & $\begin{array}{c}58.45 \\
(44.01-60.28) \\
\end{array}$ & $\begin{array}{c}0.30^{123} \\
(0.27-0.38)\end{array}$ \\
\hline & \begin{tabular}{|c} 
Age up to 50 years \\
Group 1 \\
\end{tabular} & $\begin{array}{c}327.58^{0} \\
(321.99-333.16) \\
\end{array}$ & $\begin{array}{c}144.62^{0} \\
(137.67-151.56) \\
\end{array}$ & $\begin{array}{c}27.05^{0} \\
(22.26-35.76) \\
\end{array}$ & $\begin{array}{c}51.29 \\
(42.28-60.52) \\
\end{array}$ & $\begin{array}{c}0.65^{0} \\
(0.63-0.67) \\
\end{array}$ \\
\hline & \begin{tabular}{|c|} 
Age 51-65 Group \\
2 \\
\end{tabular} & $\begin{array}{c}336.46^{0} \\
(313.83-397.17) \\
\end{array}$ & $\begin{array}{c}153.90^{\circ} \\
(94.72-195.40) \\
\end{array}$ & $\begin{array}{c}33.70^{0} \\
(21.34-108.70) \\
\end{array}$ & $\begin{array}{c}42.95 \\
(35.86-54.30) \\
\end{array}$ & $\begin{array}{c}0.80^{0} \\
(0.59-1.53) \\
\end{array}$ \\
\hline & $\begin{array}{c}\text { Age above } 65 \\
\text { Group } 3\end{array}$ & $\begin{array}{c}333.24^{0} \\
(308.94-367.90)\end{array}$ & $\begin{array}{c}112.98^{0} \\
(101.65-152.37)\end{array}$ & $\begin{array}{c}23.65^{0} \\
(10.13-35.59) \\
\end{array}$ & $\begin{array}{c}51.56 \\
(41.73-84.67) \\
\end{array}$ & $\begin{array}{c}0.88^{0} \\
(0.60-1.31)\end{array}$ \\
\hline
\end{tabular}

Note: ${ }^{0}$ - significant differences from the control (group 0), ${ }^{1,2,3}$ - significant differences with the corresponding groups $(1,2,3-$ age groups of patients) according to the Mann-Whitney criterion at $\mathrm{p}<0.05$ 


\section{DISCUSSION}

The vessels of palmar aponeurosis were studied in detail by D. Bayanbeleg [10], who distinguished arteries perforating the aponeurosis along their route to the skin with a diameter of 0.2 to $0.6 \mathrm{~mm}$ and arterioles supplying the aponeurosis with a diameter of 0.025 to $0.040 \mathrm{~mm}$. Arteries with diameters from 50 to $600 \mu \mathrm{m}$, which are classified as small arteries by the structure of their muscular membrane, which we found in histological sections of the surgical material, normally formed three non-overlapping dimensional ranges, or arteries of large, medium, and small caliber.

Transformation of the arteries of each caliber in patients with Dupuytren's contracture had its own characteristics. In small-caliber arteries, both obliterating lesions with loss of the lumen area (the first type) and signs of expansive structural remodeling (the second type) were found, in which the outer diameter and lumen of the arteries increased, despite the thickening of the intimal layer. The first type of transformation was more common in patients younger than 50 years old, the second in the older age group. Compared to the control group, arteries of the medium caliber in patients with Dupuytren's contracture were characterized not only by intimal hyperplasia, but also by thickening of the muscle layer; the most significant expansive remodeling was also noted in the older group. Large-caliber arteries in all age groups underwent constrictive remodeling: regardless of the severity of intimal hyperplasia, the outer diameter and lumen

diameter significantly decreased in comparison with the control.

The results of the study and the data that we obtained earlier [11, 12, 13] allow us to trace six stages of changes in the vessels of the palmar aponeurosis in the development of fascial fibromatosis (Table 4). The first four stages identified by us are similar to the sequence of changes in the alveolar arteries in pulmonary arterial hypertension [14, 15], studied by other authors, but adapted to the features of the palmar aponeurosis arteries. The last two stages also differ from the prototype.

The limitation of the performed study is the lack of material on the early (0-I) stages of palmar fascial fibromatosis, which are not indications for surgical treatment.

The problems of pharmacological correction in advanced stages of arterial remodeling are currently far from being resolved [15]; however, there is growing evidence in favour of complex treatment effectiveness with vasoactive drugs used in other connective tissue diseases: systemic scleroderma [16] and Peyronie's disease [17].

The distinguished types and stages of arterial remodeling are the basis for developing protocols for available additive therapy for palmar fascial fibromatosis in three categories of patients: with initial signs of fibromatosis (1), during the active progression of the contracture, when surgical treatment is inappropriate (2), for persons who underwent surgical treatment (3).

Table 4

Staging of changes in the vessels of the palmar aponeurosis in Dupuytren's contracture and the potential efficiency of therapy

\begin{tabular}{|c|l|c|}
\hline Stage & \multicolumn{1}{|c|}{ Main features } & \multicolumn{1}{|c|}{$\begin{array}{c}\text { Potential efficiency of } \\
\text { pharmacological correction }\end{array}$} \\
\hline 1 & $\begin{array}{l}\text { Vasoconstriction of arteries of large and medium caliber, hyperplasia of the } \\
\text { media of the medium caliber arteries }\end{array}$ & Effect of vasodilators is possible \\
\hline 2 & $\begin{array}{l}\text { Inflammatory infiltration and remodeling of arteries of all calibers with } \\
\text { adventitia fibrosis, hyperplasia of the inner layer of the media and / or neo- } \\
\text { intimal hyperplasia }\end{array}$ & $\begin{array}{l}\text { A “de-remodeling" effect of drugs } \\
\text { on the proliferation, migration, and } \\
\text { apoptosis of endotheliocytes and } \\
\text { smooth muscle cells is possible }\end{array}$ \\
\hline 3 & $\begin{array}{l}\text { Fibrosis of neo-intimal thickening, partial and complete obliteration of } \\
\text { arterial lumen }\end{array}$ & $\begin{array}{l}\text { Recanalization of post-occlusion blood clots and aberrant angiogenesis } \\
\text { (plexiform structures) - mainly in medium-caliber arteries }\end{array}$ \\
\hline 5 & $\begin{array}{l}\text { Compensatory progressive dilatation of small arteries, including those with } \\
\text { intact endothelial lining }\end{array}$ & $\begin{array}{l}\text { The effect of antihypoxants and } \\
\text { antioxidants with a cytoprotective } \\
\text { effect is unknown }\end{array}$ \\
\hline 6 & $\begin{array}{l}\text { Reduction of the microvasculature bed, foci of compensatory capillary } \\
\text { genesis, blood clots and plexiform structures in the veins }\end{array}$ \\
\hline
\end{tabular}

\section{CONCLUSIONS}

Dupuytren's contracture refers to diseases mediated by vascular remodeling, affecting mainly the arterial bed. In the age groups studied, arterial remodeling follows to the same pattern. Differences in histomorphometric indices in patients over 65 years of age are associated with a higher frequency of contractures in the advanced stages associated with increased comorbidity that aggravates hypoxia. 


\section{REFERENCES}

1. Wilburn J., McKenna S.P., Perry-Hinsley D., Bayat A. The impact of Dupuytren disease on patient activity and quality of life. J. Hand Surg. Am., 2013, vol. 38, no. 6, pp. 1209-1214. DOI: 10.1016/j.jhsa.2013.03.036.

2. Ulishchenko A.A., Golubev I.O. Preimushchestva i nedostatki razlichnykh metodov lecheniia bolezni Diupiuitrena [Advantages and disadvantages of various method of Dupuytren disease treatment]. Vestnik Travmatologii i Ortopedii im. N.N. Priorova, 2017, no. 2, pp. 61-68. (in Russian)

3. Calandruccio J.H., Hecox S.E. Reoperative Dupuytren contracture. In: Duncan S., ed. Reoperative Hand Surgery. New York, NY, Springer, 2012, pp. 7-15. DOI: 10.1007/978-1-4614-2373-7_2.

4. Ball C., Izadi D., Verjee L.S., Chan J., Nanchahal J. Systematic review of non-surgical treatments for early Dupuytren's disease. BMC Musculoskelet. Disord., 2016, vol. 17, no. 1, pp. 345. DOI: 10.1186/s12891-016-1200-y.

5. Tripoli M., Cordova A., Moschella F. Update on the role of molecular factors and fibroblasts in the pathogenesis of Dupuytren's disease. J. Cell Commun. Signal., 2016, vol. 10, no. 4, pp. 315-330. DOI: 10.1007/s12079-016-0331-0.

6. Mayerl C., Del Frari B., Parson W., Boeck G., Piza-Katzer H., Wick G., Wolfram D. Characterisation of the inflammatory response in Dupuytren's disease. J. Plast. Surg. Hand Surg., 2016, vol. 50, no. 3, pp. 171-179. DOI: 10.3109/2000656X.2016.1140054.

7. Ratajczak K., Augoff K., Gosk J., Taboła R., Rutowski R. Lactate dehydrogenase isoenzymes in Dupuytren's contracture. Advances in Clinical and Experimental Medicine, 2007, vol. 16, no. 2, pp. 205-211.

8. Shchudlo N., Varsegova T., Stupina T., Dolganova T., Shchudlo M., Shihaleva N., Kostin V. Arterial remodelling in palmar fascia and peculiarities of hand microhemodynamics in patients with Dupuytren's contracture. Rheumatology and Orthopedic Medicine, 2018, vol. 3, no. 2, pp. 1-7. DOI: 10.15761/ROM.1000143.

9. Tubiana R. Dupuytren's disease of the radial side of the hand. Hand Clin., 1999, vol. 15, no. 1, pp. 149-159.

10.Baitinger V.F. Klinicheskaia anatomiia ladonnogo aponevroza [Clinical anatomy of palmar aponeurosis]. Voprosy Rekonstruktivnoi i Plasticheskoi Khirurgii, 2012, vol. 40, no. 1, pp. 22-33. (in Russian)

11.Shchudlo N., Varsegova T., Stupina T., Dolganova T., Shchudlo M., Shihaleva N., Kostin V. Assessment of palmar subcutaneous tissue vascularization in patients with Dupuytren's contracture. World J. Orthop., 2018, vol. 9, no. 9, pp. 130-137. DOI: 10.5312/ wjo.v9.i9.130.

12.Dolganova T.I., Shchudlo N.A., Shikhaleva N.G., Kostin V.V. Morfofiziologicheskie kharakteristiki tipov mikrotsirkuliatsii kozhi u patsientov s kontrakturoi Diupiuitrena [Morphophysiological characteristics of skin microcirculation types in patients with the Dupuytren contracture]. Regionarnoe Krovoobrashchenie i Mikrotsirkuliatsiia, 2018, vol. 17, no. 4 (68), pp. 24-32. (in Russian) DOI: 10.24884/1682-6655-2018-17-4-24-32.

13.Dolganova T.I., Shchudlo N.A., Shabalin D.A., Kostin V.V. Otsenka gemodinamiki arterii kisti i mikrotsirkuliatsii kozhi pri kontrakture Diupiuitrena 3-4 stadii do i posle operativnogo lecheniia s primeneniem chreskostnoi fiksatsii po G.A. Ilizarovu [Assessment of hemodynamics of the hand arteries and skin microcirculation in Dupuytren's contracture stages 3 to 4 before and after surgical treatment with the use of Ilizarov transosseous fixation]. Genij Ortopedii, 2019, vol. 25, no. 1, pp. 86-92. (in Russian) DOI: 10.18019/1028-4427-2019-25-1-86-92.

14. Heath D., Edwards J.E. The pathology of hypertensive pulmonary vascular disease; a description of six grades of structural changes in the pulmonary arteries with special reference to congenital cardiac septal defects. Circulation, 1958, vol. 18, no. 4, part 1, pp. 533547. DOI:10.1161/01.cir.18.4.533.

15.McLaughlin V.V., Shah S.J., Souza R., Humbert M. Management of pulmonary arterial hypertension. J. Am. Coll. Cardiol., 2015, vol. 65, no. 18, pp. 1976-1997. DOI: 10.1016/j.jacc.2015.03.540.

16.Alekperov R.T. Lechenie sistemnoi sklerodermii [Treatment of systemic scleroderma]. Sovremennaia Revmatologiia, 2011, no. 3, pp. 18-24. (in Russian)

17.Levine L.A. Peyronie's disease: contemporary review of non-surgical treatment. Transl. Androl. Urol., 2013, vol. 2, no. 1, pp. $39-44$. DOI: $10.3978 /$ j.issn.2223-4683.2013.01.01.

Рукопись поступила 25.02.2020

Information about the authors:

1. Natalia A. Shchudlo, M.D., Ph.D., Ilizarov National Medical Research Centre for Traumatology and Orthopedics, Kurgan, Russian Federation, Email:nshchudlo@mail.ru

2. Tatyana N. Varsegova, Ph.D. of Biological Sciences, Ilizarov National Medical Research Centre for Traumatology and Orthopedics, Kurgan, Russian Federation, Email: varstn@mail.ru

3. Tatyana A. Stupina, Ph.D. of Biological Sciences, Ilizarov National Medical Research Centre for Traumatology and Orthopedics, Kurgan, Russian Federation, Email: StupinaSTA@mail.ru

4. Mikhail M. Shchudlo, M.D., Ph.D., Ilizarov National Medical Research Centre for Traumatology and Orthopedics, Kurgan, Russian Federation 